\title{
Mulheres, trabalhos e histórias: uma análise das trajetórias de vida em uma Comunidade Teuto-Brasileira do RS
}

\author{
Tatiana Souza de Camargo ${ }^{1}$, Muriel Closs Boeff ${ }^{2}$ \\ ${ }^{1}$ Universidade Federal do Rio Grande do Sul - UFRGS. Departamento de Ensino e Currículo, Faculdade de Educação, \\ Programa de Pós-Graduação em Educação em Ciências. Campus ICH ISP FAE. Avenida Paulo Gama, 110. Farroupilha. Porto \\ Alegre - RS. Brasil. ${ }^{2}$ Universidade Federal do Rio Grande do Sul - UFRGS. \\ Autor para correspondência/Author for correspondence: tatiana.camargo@ufrgs.br
}

RESUMO. Este artigo apresenta as intersecções entre duas pesquisas realizadas em um mesmo município de colonização alemã, localizado na Encosta da Serra Gaúcha/RS. Ambas utilizaram ferramentas etnográficas de pesquisa, como entrevistas e observação participante registrada na forma de diário de campo, analisadas de maneira combinada. A primeira, realizada em Grupos de Mulheres e com representantes das Secretaria de Agricultura, Educação e do Sindicato dos Trabalhadores Rurais buscou investigar a sucessão geracional na agricultura familiar do município, focalizando nas mulheres jovens. A segunda realizou-se em uma Equipe de Estratégia de Saúde da Família, com usuárias que possuem diagnóstico de depressão, procurando compreender as experiências e significados envolvidos no processo de construção deste diagnóstico. Consideramos que as análises traçadas a partir destes movimentos de pesquisa trazem preciosas contribuições para que seja pensada a organização da comunidade, principalmente em termos de alternativas de trabalho e estratégias educativas em Educação do Campo que sejam capazes de promover a sucessão geracional da agricultura familiar no município e de incorporar a temática de gênero, gerando assim um real incremento em termos de qualidade de vida desta população.

Palavras-chave: Gênero, Educação, Trabalho, Qualidade de Vida, Saúde Mental. 


\title{
Women, Works and Stories: An Analysis of Life Trajectories in a Teuto-Brazilian Community of RS
}

\begin{abstract}
This article presents the intersections between two studies conducted in the same municipality of German colonization, located in the Encosta da Serra Gaúcha / RS. Both used ethnographic research tools, such as interviews and participant observation recorded as a field diary, analyzed in a combined manner. The first, held in Women's Groups and with representatives of the Agriculture and Education Sector and the Rural Workers' Union, sought to investigate the generational succession in the family agriculture of the municipality, focusing on young women. The second was carried out in a Family Health Strategy Team, with users diagnosed with depression, trying to understand the experiences and meanings involved in the process of constructing this diagnosis. We consider that the analyzes drawn from these research movements bring valuable contributions so that the community organization is considered, especially in terms of work alternatives and educational strategies in Countryside Education that are capable of promote the generational succession of family agriculture in the municipality and to incorporate the theme of gender, thus generating a real increase in terms of the quality of life of this population.
\end{abstract}

Keywords: Gender, Education, Work, Quality of Life, Mental Health. 


\section{Mujeres, Trabajos e Historias: Un Análisis de las Trayectorias de Vida en una Comunidad Teuto-Brasileña del RS}

RESUMEN. Este artículo presenta las intersecciones entre dos investigaciones realizadas en un mismo municipio de colonización alemana, ubicado en la Encosta da Serra Gaúcha / RS. Ambos utilizaron herramientas etnográficas de investigación, como entrevistas y observación participante registrada en forma de diario de campo, analizadas de manera combinada. La primera, realizada en Grupos de Mujeres y con representantes de la Secretaría de Agricultura, Educación y del Sindicato de los Trabajadores Rurales, buscó investigar la sucesión generacional en la agricultura familiar del municipio, enfocándose en las mujeres jóvenes. La segunda se realizó en un Equipo de Estrategia de Salud de la Familia, con usuarias que poseen diagnóstico de depresión, buscando comprender las experiencias y significados involucrados en el proceso de construcción de este diagnóstico. Consideramos que los análisis trazados a partir de estos movimientos de investigación traen preciosas contribuciones para que sea pensada la organización de la comunidad, principalmente en términos de alternativas de trabajo y estrategias educativas en Educación del Campo que sean capaces de promover la sucesión generacional de la agricultura familiar en el municipio y de incorporar la temática de género, generando así un real incremento en términos de calidad de vida de esta población.

Palabras-clave: Género, Educación, Trabajo, Calidad de Vida, Salud Mental. 


\section{Introdução}

Buscamos apresentar, neste artigo, o resultado da intersecção entre duas pesquisas realizadas por mulheres e com mulheres que residem em uma mesma comunidade: o município de Santa Maria do Herval/RS. Localizado na região da Encosta da Serra Gaúcha, o pequeno município de paisagens montanhosas e vegetação abundante se localiza há cerca de $80 \mathrm{~km}$ de Porto Alegre, possui uma área de $139,6 \mathrm{~km}^{2}$ e uma população estimada de 6.295 habitantes para o ano de 2013 (IBGE, 2014). Sua história é fortemente marcada pela colonização alemã, iniciada na região em meados do século XIX. Por volta de 1844, chegaram os primeiros colonos à linha Herval, onde hoje se situa a sede do município, que apresentava um solo mais propício para o cultivo. Daí originou-se o nome atual do município, conhecido como Teewald por seus habitantes (Braun et al., 2009; Woortmann, 2000).

Desenvolvida por famílias de origem alemã, para os quais o pertencimento étnico, o aprendizado do hunsrik ${ }^{i}$ como língua materna, a forte religiosidade, os laços comunitários e de vizinhança são notoriamente presentes, a agricultura familiar hervalense guarda algumas singularidades, partilhadas com outros municípios vizinhos da chamada Colônia Velha alemã ${ }^{\text {ii }}$

Para este trabalho, a singularidade que merece destaque é a pluriatividade observada na produção rural do município. Nesse sentido, é comum observar propriedades nas quais além das atividades agrícolas tipicamente desenvolvidas no município - como a olericultura, a pequena produção de leite, a lavoura de milho e feijão, a silvicultura de acácia, a piscicultura em pequena escala, a avicultura, a fruticultura, a lavoura de batata - estarem combinadas entre si, elas também, na maioria dos casos, se articulam a um elemento externo: o trabalho de algum(ns) membro(s) da família em atividades industriais urbanas, notadamente nas empresas de calçados.

A pluriatividade é um conceito desenvolvido por estudiosos dos campos do Desenvolvimento Rural e Agricultura, voltados ao trabalho com pequenos produtores familiares, e designa as unidades produtivas multidimensionais, nas quais são praticadas a agricultura e outras atividades, tanto dentro como fora da propriedade, pelas quais são recebidos diferentes tipos de remuneração e receitas (Fuller, 1990 como citado em Schneider, 2004).

Esse caráter pluriativo e multidimensional parece ser uma 
característica desta região, na qual o desenvolvimento da indústria calçadista, ocorrido ao longo da década de 1980 e marcado pela instalação de sedes em localidades rurais, esteve organicamente ligado à estrutura produtiva local seja relacionando-se dinamicamente com as formas de trabalho na agricultura familiar, através do assalariamento dos colonos, seja pela externalização de partes do processo produtivo para serem confeccionados fora da fábrica, em pequenos ateliês (para os quais as empresas terceirizam certos serviços), ou até mesmo em casa (Schneider, 2004).

Esse fenômeno de incorporação de atividades da indústria calçadista ao modo de vida do agricultor familiar da Região da Encosta da Serra operando sua ressignificação e atuando, de certa maneira, na sua manutenção é bastante interessante e nos mostra a complexidade do cenário investigado. Nos trabalhos desenvolvidos por Schneider (2004) na região do Vale dos Sinos na década de 1990, uma das principais constatações foi a de que:

O desenvolvimento da indústria calçadista articulou-se com a agricultura familiar e que as transformações das atividades agrícolas, sobretudo mudanças ocasionadas no processo de produção podem ser atribuídas ao seu assalariamento nas fábricas de calçados e curtumes. O que parece singular nesse processo é o tipo de relação de trabalho que se estabeleceu ... Os efeitos da industrialização sobre a agricultura familiar não chegam a provocar, de fato, o êxodo das populações rurais para as cidades. $\mathrm{O}$ assalariamento constituiu-se, neste caso, numa alternativa estratégica às dificuldades enfrentadas pelos colonos ... Os empregos fora da propriedade [se tornaram, assim] uma opção com dupla vantagem: obter rendas $\mathrm{e}$ ganhos econômicos para garantir a subsistência familiar e ter a possibilidade de permanecer residindo na propriedade agrícola (Schneider, 2004, p. 111, entre chaves comentários meus).

Nesse sentido, o autor conclui que a peculiar forma de inter-relação entre as formas de trabalho e de produção das indústrias de calçados e dos agricultores familiares está entre as principais razões que explicam o vigoroso crescimento econômico e as profundas transformações sociais que se registraram na região da Colônia Velha alemã a partir da década de 1970 (Schneider, 2004).

Com relação à divisão dos trabalhos que compõem a pluriatividade da agricultura familiar hervalense, é importante marcar que essa se orienta por princípios de hierarquia e de gênero. Nessa divisão, em geral, o marido/pai fica na propriedade desenvolvendo as atividades agrícolas e a mulher e/ou filhos e filhas jovens saem para trabalhar nas empresas de calçados. Nesse esquema, o trabalho do marido/pai é compreendido como a 
atividade principal para o sustento da família e o trabalho feminino e dos filhos(as) funciona como uma "ajuda em casa" (Machado \& Menasche, 2012).

$\mathrm{Na}$ tentativa de traçar os possíveis entrelaçamentos que se tecem entre sucessão geracional, educação, trabalho e qualidade de vida $\quad-$ focalizando especificamente no aspecto da saúde mental - nas trajetórias de vida de mulheres deste município, vinculadas à agricultura familiar local, mesclamos os dois trabalhos e construímos as discussões e análises que constituem este artigo.

\section{Metodologia}

Além de estabelecer relações a partir dos trabalhos realizados com a mesma comunidade em um mesmo território, ambas as pesquisas apresentam caminhos metodológicos semelhantes, com o uso de ferramentas etnográficas de pesquisa, tais como entrevistas abertas e semi estruturadas e a observação participante registrada na forma de diário de campo, analisadas de maneira combinada.

A primeira tem se realizado a partir da observação participante nas reuniões dos seis Grupos de Mulheres organizados pelo Sindicato dos Trabalhadores Rurais de Santa Maria do Herval em parceria com o escritório municipal da Empresa de
Assistência Técnica e Extensão Rural (EMATER/RS), aliada às entrevistas abertas com representantes da Secretaria de Agricultura, da Secretaria de Educação e da presidência do mencionado Sindicato.

A segunda acontece em uma Equipe de Estratégia de Saúde da Família (ESF) do município, tendo como amostra usuárias da unidade, autodeclaradas mulheres, maiores de 18 anos, com diagnóstico de depressão, a partir da observação participante em ações de promoção da saúde e 18 entrevistas semi estruturadas.

Destacamos que ambos os projetos de pesquisa foram aprovados pelo Comitê de Ética em Pesquisa da Universidade Federal do Rio Grande do Sul (CAAE 77833517.9.0000.5347 e CAAE 69593617.6.0000.5347) e que os nomes apresentados ao longo do texto são fictícios a fim de preservar o sigilo das participantes.

\section{A atualidade deste contexto: sucessão geracional e questões de gênero}

Quase 30 anos após os estudos de Schneider (2004) sobre a pluriatividade da agricultura familiar na Colônia Velha alemã, buscamos revisitar um pedaço do campo de sua pesquisa, a fim de investigar dois elementos específicos, quais sejam, a sucessão geracional das famílias 
agricultoras $\mathrm{e}$ as questões de gênero $^{\mathrm{iii}}$ implicadas na divisão de tarefas produtivas, visto que na maioria dos casos são as mulheres que diariamente deixam a propriedade e vão trabalhar nas empresas de calçados.

Ao longo das entrevistas abertas realizadas com o representante da Secretaria de Agricultura e da presidência do Sindicato dos Trabalhadores Rurais, assim como nas observações conduzidas nas reuniões dos Grupos de Mulheres, a questão da sucessão geracional no campo é narrada como a principal preocupação em termos de reprodução social do modo de vida dos agricultores familiares de Santa Maria do Herval, assim como se observa em estudos realizados junto a agricultores familiares em municípios de colonização alemã no Vale do Taquari (Gaviria \& Menasche, 2006; Gaviria \& Pezzi, 2007; Wedig \& Menasche, 2009).

Entendemos a sucessão geracional como a "transferência de poder e do patrimônio entre gerações no âmbito da produção agrícola familiar, a retirada paulatina das gerações mais idosas da gestão do estabelecimento e a formação profissional de um novo agricultor(a)" (Stropasolas, 2011). Além da transferência material da propriedade, a sucessão geracional na agricultura familiar envolve um processo de transferência de saberes e fazeres, de manutenção de um patrimônio histórico e sociocultural particular, processo o qual parece estar sofrendo uma forte tendência de ruptura, o que corrobora a preocupação manifesta nas entrevistas.

Ao detalharmos, durante as conversas, a problemática da sucessão geracional no município, os entrevistados afirmam perceber que aos jovens faltam incentivos dos pais, dos professores e da comunidade escolar como um todo para a escolha de uma atuação profissional ligada ao campo e à agricultura familiar.

Mobilizadas por tais afirmações, buscamos conversar com representantes da Secretaria Municipal de Educação, assim como com representantes das Escolas Estaduais do município, a fim de levantar dados sobre a existência e a historicidade de práticas de Educação do Campo vinculadas às escolas do município, o que vimos detalhar na seguinte seção.

Antes no entanto, é importante delimitar que neste trabalho entendemos que Educação do Campo é toda ação educativa desenvolvida junto às populações do campo e fundamenta-se nas práticas sociais constitutivas destas populações, quais sejam os seus conhecimentos, habilidades, sentimentos, valores, modos de ser, de viver, de perceber, de produzir e compartilhar a vida (CNE/CEB, 2002). Entendemos ainda que 
estas ações educativas podem tanto desenvolver-se em escolas do campo como em outros espaços educativos, como as práticas relacionadas à assistência técnica e extensão rural, os encontros de formação sindical, assim os grupos de mulheres e atividades de promoção da saúde nos quais se desenvolveu esta pesquisa e que serão trazidos mais adiante no texto.

\section{Escola no Campo? Escola do Campo?}

Com relação à educação escolar, atualmente o município é atendido por uma rede que conta com quatro escolas municipais que oferecem o Ensino Fundamental completo, uma escola municipal de Educação Infantil dividida em três sedes, uma escola estadual que oferece o Ensino Fundamental completo e uma escola estadual que oferece o Ensino Fundamental completo e o Ensino Médio. Com relação às matrículas realizadas no ano de 2017, o município contabiliza um total de 1049 estudantes, sendo 284 na Educação Infantil, 593 no Ensino Fundamental e 172 no Ensino Médio.

Em consulta realizada junto ao Setor Pedagógico da Secretaria Municipal de Educação, foi constatado que as duas escolas municipais de Ensino Fundamental são consideradas como Escolas do Campo, contando com turmas multisseriadas. No entanto, conforme $\mathrm{o}$ relato dos responsáveis pelo setor, não são desenvolvidas atividades específicas que pudessem ser classificadas como iniciativas em Educação do Campo. Com relação à Educação Infantil, as três sedes se localizam nas áreas urbanizadas do município, nas quais se localizam as maiores sedes das empresas de calçados. Ainda relacionada à Educação Infantil, constatou-se que não há espera para se conseguir uma vaga neste nível de ensino.

Compreendemos por escolas do campo as instituições que têm sua sede no espaço geográfico classificado como rural pelo IBGE, assim como as identificadas com o campo, mesmo tendo sua sede em áreas consideradas urbanas, sendo neste caso assim consideradas pois atendem populações de comunidades cujo produção econômica, social e cultural está, majoritariamente, vinculada ao campo, como é o caso de Santa Maria do Herval (MEC/CNE， 2001; CNE/CEB， 2002, 2007).

Segundo entrevista aberta, realizada com a Supervisora Pedagógica das escolas municipais, não existem iniciativas alinhadas com a Educação no Campo no município. Ela relata ter participado de um Curso de Extensão em Porto Alegre, relativo ao Programa Nacional de Educação no Campo (PRONACAMPO) e 
também de um Curso de Especialização com 340 horas de aula relativo ao programa Escola Ativa, do Ministério da Educação. Após estas experiências, ela relata ter organizado reuniões mensais de formação com os professores da rede municipal, durante um ano. No entanto, segundo a Supervisora, os professores não concordaram muito com essas "ideias de Educação no Campo":

Eles acreditam que a Educação no Campo está muito aquém da educação urbana, muito defasada com relação ao que já era trabalhado por eles nas escolas ... Sabe, você ter um trabalho para que as pessoas continuem no campo, isso não ocorre nas nossas escolas, o nosso aluno não quer trabalhar no campo ... Se você for ver, as nossas escolas são bem urbanas, não preparam para o trabalho rural, não que elas preparem para o trabalho na fábrica também, mas... (Fala registrada durante entrevista aberta com a Supervisora Pedagógica das escolas municipais).

Com relação às duas escolas estaduais, fomos informadas que ambas são consideradas "escolas urbanas", por se localizarem nas áreas mais urbanizadas da cidade, apesar de uma grande parcela dos alunos atendidos serem oriundos de localidades rurais, filhas e filhos de agricultores familiares. De acordo com os responsáveis pelo setor, somente para o Ensino Médio, a estimativa é de que cerca de $70 \%$ dos alunos, em sua maioria mulheres jovens, venham das localidades rurais para estudar no Centro do município (120 dos 172 do total de alunos). Quando motivados a compartilhar sobre suas experiências e expectativas com a Educação do Campo, um dos diretores comentou:

Nós somos considerados uma escola urbana, o que financeiramente nem é vantajoso, pois em termos de valores da merenda escolar, por exemplo, as escolas do campo ganham dez centavos a mais por aluno... Mas eu não sei, acho que essa é uma tendência talvez sem volta, essa centralização das escolas, sabe. Por que se tu anda pelas localidades, dá para ver os prédios das escolas fechadas. Eu acredito que tenha umas dez escolas fechadas. Me lembro da situação da escola da Vila Saeger, teve épocas que tinha cinco alunos, aí eles fecharam, sabe, por uma questão de economia, e preferem trazer todos de ônibus para o Centro. Mas se a gente vai pensar, eles poderiam manter algumas dessas escolas e economizar em transporte escolar, né? Como eu disse, é uma situação complicada e não sei até que ponto isso tem volta (Fala registrada durante entrevista aberta com Diretores e Coordenadores Pedagógicos das escolas estaduais).

As falas apresentadas reforçam a narrativa dos entrevistados vinculados à Secretaria de Agricultura e ao Sindicato dos Trabalhadores Rurais no sentido de mostrar que as escolas do município podem até estar no campo, mais ainda não são do campo e nem para o campo e, desta forma, carecem de uma trabalho que valorize o modo de vida da agricultura 
familiar e que, ao se pautar territorialidade local $^{\text {iv }}$, possa construir conhecimentos que potencializem o desenvolvimento local e talvez apontem possibilidades de enfrentamento da questão da sucessão geracional.

\section{Mulheres e o trabalho na empresa de calçados}

Se o modo de vida do colono como um todo foi narrado pelos entrevistados como em franca situação de vulnerabilidade, em termos de reprodução material e social, devido ao pequeno número de jovens que escolhem permanecer no campo, as mulheres jovens foram coletivamente identificadas como um elemento-chave a ser investigado e considerado. Isto porque, dentre a parcela de jovens que voluntariamente optam por uma atuação profissional ligada à produção no campo, as mulheres são minoria absoluta.

Buscando aproximar-se das atividades educativas direcionadas ao público feminino, passamos a acompanhar a reuniões dos Grupos de Mulheres Agricultoras, realizado desde 2001 pelo escritório municipal da EMATER/RS, em parceria com o Sindicato dos Trabalhadores Rurais, em seis diferentes localidades (Canto Becker, Padre Eterno Alto, Alto Morro dos Bugres, Morro dos
Bugres Baixo, Vila Seger e Vila Kunst). Os grupos são formado por uma média de 15 mulheres cada um, a maioria delas com idades acima de 50 anos de idade. Nos encontros mensais desses grupos é trabalhado $\mathrm{o}$ resgate de receitas tradicionais e a confecção do artesanato como uma possibilidade de renda extra para essas mulheres participantes, juntamente com discussões relevantes para as mulheres trabalhadoras rurais, como temas ligados às propostas de Reforma da Previdência e seus impactos para a aposentadoria rural, por exemplo.

Para os responsáveis pelas entidades que atuam junto aos agricultores familiares, as mulheres jovens não têm muito interesse em procurar os cursos por eles oferecidos ${ }^{\mathrm{v}}$, e raramente participam dos Grupos de Mulheres, como evidencia a fala de um extensionista entrevistado:

As moças, tu vê, elas não pensam em uma formação que ajude na propriedade. Como a nossa antiga estagiária, que saiu daqui da EMATER e foi para a fábrica porque ia ganhar mais. Ela não via seu trabalho aqui como uma possibilidade de aprender. É como a maior parte das jovens, o que elas querem mesmo é trabalhar na fábrica, casar, comprar terreno, construir, deixar ela bonita... Elas querem uma casa bonita, com coisas dentro e por isso elas vão pra fábrica (Fala registrada durante entrevista com extensionistas da EMATER/RS). 
Assim, as atividades profissionais para as quais as mulheres jovens são prioritariamente atraídas são aquelas desenvolvidas nas empresas de calçados. Cabe salientar que o dualismo que os entrevistados constroem entre agriculturafábrica, em correspondência com ruralurbano, vai de encontro ao caráter de pluriatividade que estudos do campo do Desenvolvimento Rural apontam como uma singularidade da região na qual se encontra Santa Maria do Herval, e que seria um dos fatores para a manutenção da agricultura familiar na região (Schneider, 2004).

Nesse sentido, o trabalho feminino na empresa de calçados talvez não deva ser compreendido como um elemento externo ao funcionamento da família agricultora, mas como uma maneira de complementar o orçamento familiar, condizente com os princípios de hierarquia e gênero que tradicionalmente definem o processo de trabalho de cada membro, dentro das famílias agricultoras do município de Santa Maria do Herval (Maia, 2004; Schneider, 2004).

Dentre as mulheres mais velhas participantes dos Grupos, algumas relatam ter trabalhado nas fábricas de calçado em algum momento de sua vida, e trazem experiências bastante variadas. Para algumas representou a possibilidade de ter uma renda própria e a oportunidade de sair de casa e se relacionar mais com outras mulheres, mesmo que esse rendimento tivesse que ser entregue para o pai ou marido administrar, ele era clara e indubitavelmente produção sua, de seu esforço. Para outras foi um acontecimento mais doloroso, de rompimento com sua cultura de trabalho na roça:

Eu me lembro de estar na fábrica, e daí fazer um dia bonito, eu podia ver as pessoas passando e ficava pensando, ah, agora é época de colher batata, e eu ficava triste, eu chorava ... eu queria estar na roça, fazer o serviço com o pai e a mãe (Fala de participante de um Grupo de Mulheres, registrada no Diário de Campo).

Seja como for a natureza das memórias, as mulheres dos Grupos concordam em um ponto muito importante: a fábrica de calçados atual não é mais a que elas trabalhavam. $\mathrm{O}$ ambiente, os processos e as relações mudaram muito. Há trinta anos atrás as empresas tinham mais a feição de um ateliê, com muitas etapas do processo de produção do calçado sendo realizadas de forma artesanal. Muitas se localizavam nas áreas rurais, instaladas em antigos salões de baile, e junto com as marteladas e as máquinas de costura se ouvia música e conversava.

Com a crise enfrentada em meados da década de 1990 pelo do setor calçadista da região, em constante disputa de 
mercado com as empresas da China, a produção de calçados se modificou muito. Os processos se tornaram mais mecanizados, controlados, cronometrados. As cadeiras foram retiradas, o trabalho na fábrica hoje se organiza ao longo de esteiras, com funções definidas para cada trabalhador.

No que tange ao trabalho juvenil e feminino nas empresas de calçados, narrado como uma atividade disciplinante, repetitiva e desempenhada sob grande pressão, cabe destacar a sensação partilhada pelos moradores/trabalhadores hervalenses da decadência do setor, reforçada por recorrentes manchetes dos jornais locais, que anunciam o fechamento de filiais de empresas calçadistas resultando na realocação e demissão de funcionários, o que lhes causa insegurança e ansiedade ao comprometer sua qualidade de vida.

Em nossas pesquisas utilizamos o conceito de qualidade de vida tal como esse é definido por Sen (2001), isto é, como sendo a representação de combinações entre as capacitações, coisas que uma pessoa/grupo é capaz de fazer ou ser, e funcionalidades, as várias coisas que uma pessoa/grupo faz ou é, de uma pessoa ou coletivo. Isto significa dizer que a qualidade de vida pode ser avaliada em termos da capacitação para alcançar as funcionalidades (desde nutrir-se, ter saúde, educação até autorrespeito e integração social), sustentando que o desenvolvimento humano em seu pleno sentido é alcançado à medida que as pessoas/grupos passam a ter maiores possibilidades de opção e disposição de capacidades e meios para tal feito - ficando em um plano secundário a importância de recursos como renda, capital e posse de recursos físicos, ao destacar o papel das capacidades e habilidades que os indivíduos precisam ter para poder fazer as escolhas e alcançar uma vida plena de bem-estar. Vale ressaltar ainda que, considerando tal compreensão, a ampliação da qualidade de vida de uma pessoa/coletivo social/sociedade não pode ser um processo que assevere a vulnerabilidade e a precariedade da vida daqueles que não são contemplados (Sen, 2001; Schneider \& Freitas, 2013).

Neste sentido, consideramos que a escassez de opções de trabalho e a falta de atividades educativas direcionadas especificamente a promover o diálogo das mulheres jovens com outras possibilidades de atividades produtivas, inclusive ligadas à agricultura familiar, parecem comprometer a sua qualidade de vida - e em decorrência de suas famílias e da comunidade - o que ao longo dos anos pode ir se traduzindo tanto em 
esvaziamento da agricultura familiar no município quanto em adoecimento da população.

Um dado que parece reforçar tal consideração é o alto índice o número de consultas em saúde mental realizadas no município. Segundo dados obtidos para o ano de 2016 na Secretaria Municipal de Saúde, através do Sistema Único de Saúde $\begin{array}{lll}\text { (SUS) foram realizados } & 1.059\end{array}$ atendimentos de psiquiatria, sendo 710 de mulheres e 349 de homens, e 667 atendimentos de psicologia, 503 de mulheres e 164 de homens ${ }^{\text {vi }}$.

Instigadas por esses números, passamos a desenvolver a segunda pesquisa a ser discutida neste texto, a qual trata especificamente da temática da depressão em mulheres, buscando compreender as experiências individuais e coletivas com essa condição, seus significados no dia-a-dia e buscar possibilidades de enfrentamento da questão, o que trazemos a seguir.

\section{Mulheres, trajetórias de vida e saúde mental}

No segundo movimento de pesquisa buscamos discutir como determinados modos de viver, sentir e interpretar as condições de saúde mental, tanto por pacientes quanto por profissionais, pode estabelecer relação com a construção do diagnóstico de depressão nesta comunidade, englobando a articulação do marcador social gênero com a organização do trabalho, com a posição ocupada pelas mulheres e com a organização da cultura teuto-brasileira no local.

Concordamos com Helman (2009), que ao considerar a influência do gênero ou da cultura sobre determinada experiência de adoecimento, afirma ser fundamental situar o contexto de onde se fala. Ou seja, seria um engano pensar que em uma cultura de hegemonia masculina/feminina, branca, com grupo social economicamente favorecido, no continente europeu, as vivências e internalizações sobre o significado de uma doença poderiam ser as mesmas que em um contexto de hegemonia masculina/feminina, negra, em um grupo social economicamente desfavorecido, no continente sul americano, ou vice-versa, pois cada grupo, dentro de suas singularidades, reconhece ou não determinados sintomas, sinais ou alterações de comportamento como reflexo de saúde ou doença.

Sabe-se que "cada cultura oferece aos seus membros os modos de tornar-se "doente", de moldar seu sofrimento em uma entidade nosológica reconhecível, de explicar sua causa e obter algum tratamento para ela" (Helman, 2009, p. 
233, grifos do autor). Dessa maneira, se o gênero é fator constituinte da identidade dos sujeitos sendo construído a partir de aspectos relacionais e sociais, os quais transitam nos mais diferentes contextos políticos, econômicos e culturais, poderia se pensar que a forma como uma mulher ou um homem hoje, no século XXI, vive sua experiência do adoecimento pode estar sendo influenciada pelas relações de gênero e pelo contexto cultural onde está inserida(o).

As falas trazidas para a análise a seguir foram obtidas a partir das entrevistas realizadas com as mulheres que se dispuseram a participar do estudo, sendo estas gravadas e depois transcritas.

Nas trajetórias de vida de mulheres na faixa etária dos 50 anos, observou-se o envolvimento em atividades de trabalho desde a infância, nas quais se destacam, inicialmente, a responsabilidade pelo cuidado dos irmãos menores e das tarefas de casa e, posteriormente, o trabalho na fábrica com o intuito de auxiliar financeiramente a família, o que pode ser visto na fala de Sandra, 51 anos, aposentada, que trabalhava desde os 11 anos para auxiliar no sustento da família:

- Nós era responsável, a mãe ela me dava e nós tinha que comprar fralda de pano, não era fralda que nem agora descartável, fralda de pano, roupa pra nenê, era tudo pras outras crianças, era tudo, era como se nós tivesse uma família, sabe? Com essa idade a gente já tinha uma família, era responsável pela família... As responsabilidade era nossa, nós era pai, mãe, irmão, tudo ao mesmo tempo. Era muito complicado. (silêncio).

Ainda nesta mesma faixa etária, é bastante presente o relato da importância da indústria de calçados como uma oportunidade de renda estável, propiciando que a família continuasse a viver no município. Neste sentido, observaram-se casos de mulheres agricultoras de origem alemã que migraram de Santa Catarina, juntamente com suas famílias, em busca da qualidade de vida que o trabalho na indústria calçadista, que se desenvolvia na Encosta da Serra, poderia lhes oferecer. Nádia, 53 anos, mudou-se para Santa Maria do Herval em busca de emprego, e suas falas trazem relatos desta migração.

Pesquisadora: - E daí Nádia, depois que vocês vieram de Santa Catarina tu sempre trabalhou na fábrica?

Nádia: - Sim, daí sempre na fábrica.

Pesquisadora: - Como era?

Nádia: - Ai, era bom, era judiado também, mas a gente trabalhava e não perdia uma hora de serão, toda noite se tinha serão nós fazia, porque a gente queria né? Pra conseguir se colocar, pra se ajeitar na vida né? Era só isso que a gente queria.

Outro elemento surgido no relato de Nádia foi a inviabilidade da continuidade da educação escolar, e do impacto que essa 
condição the causou frente à possibilidade de escolha de uma profissão e das posteriores consequências que isto pode ter acarretado para sua saúde mental.

Pesquisadora: - Então Nádia, em relação as profissões, sempre foi na roça e na fábrica...

Nádia: - Isso, só.

Pesquisadora: - Tu gostaria de ter escolhido alguma outra profissão, se tu pudesse escolher?

Nádia: - Iá, o que a gente ia escolher? Estudo não tinha.

Pesquisadora: - Mas hoje assim, quando tu pensa, se tu pudesse ter tido a chance de escolher, o que tu gostaria de ter feito?

Nádia: - Eu queria muito ter ido estudar, isso eu sempre queria muito, mas os velhos não tinham condição. Imagina, eu saí da aula com 11 anos, eu tinha passado a quarta série daí eu fiquei em casa, tinha que trabalhar.

Pesquisadora: - E tu queria estudar pra ser o quê?

Nádia: - Sabe o que eu queria muito? Eu vou te falar: eu queria estudar pra freira, e eles não deixaram. Daí quem sabe hoje eu tava bem.

Ao narrarem suas histórias de vida, as mulheres de mais de 40 anos, que em geral trabalharam em atividades agrícolas em sua infância/juventude, representam essa vivência como uma atividade fisicamente exaustiva.

Pesquisadora: - E esse problema na coluna tem a ver com trabalho? Nádia: - Diz o médico que sim. Pesquisadora: - Sempre trabalhou na fábrica?

Nádia: - Não, de nova na roça, muito pesado, serviço muito pesado. Nós tinha que trabalhar demais, né? Então diz o médico que é de serviço pesado que isso vem e a gente era novo né?

Pesquisadora: - Quantos ano tu tinha quando tu começou a trabalhar na roça?

Nádia: - 6, 7 anos. 7 anos já tinha uma enxadinha pra limpar amendoim, arroz, aipim. Meio dia na aula com 7 anos e meio dia na roça. Fazer o tema de noite em casa, luz elétrica não tinha, tinha um lampiãozinho. Isso é sofrimento. $\mathrm{O}$ meu irmão mais velho tá na mesma situação que nem eu, tem dias que não caminha mais. E ele tinha 11,12 anos ele ficava atrás do arado, lavrando.

A organização fortemente hierarquizada da família e da propriedade, na qual a figura central coloca-se sobre o pai, também pode ser percebida na trajetória de vida narrada por Nádia, trazendo consequências para ela e para outros membros da família.

Nádia: - O meu irmão mais velho casou com 19 anos na marra porque não aguentou mais em casa. $\mathrm{O}$ pai era, meu Deus do céu, era ruim. E isso a gente tem dentro da gente né? Isso é tudo que tá acumulado.

Pesquisadora: - Tu acha que a tua depressão tem a ver com isso?

Nádia: - Muito! Muito, muito, muito, muito! E daí quando eu começo a pensar assim, eu não posso falar muito, eu só tenho, só me passa outras coisas na cabeça. Daí eu penso: por que eu tinha que sofrer tanto? (longo silêncio, chora).

Da mesma forma, o controle patriarcal e seus reflexos nas relações de gênero foram trazidos: 
Nádia: - Eu tinha, como é que eu vou te dizer, eu acho que eu tinha uns 13 pra 14 anos. Nós morava no interior, a mãe tinha muita galinha, tinha vaca de leite, tinha tudo, fazia queijo. Daí a mãe dizia pra mim: tu pega, só escuta a história! Tu leva ovos, manteiga e queijo pra cidade, tu vende e daí tu vai no mercado e daí tu traz isso, traz isso e traz aquilo. Assim, a mãe se virava, porque $\mathrm{o}$ véio botou tudo fora $\mathrm{o}$ dinheiro, dinheiro não tinha, o pai botava tudo fora. Daí eu já era uma mocinha né, 13 pra 14 anos. Daí eu disse pra mãe: eu vou, daí eu compro as coisas que falta, vou no mercado, mercado Itaú em Pinhalzinho e daí eu disse: e se sobrar mãe eu posso comprar um shampoo pra mim? $\mathrm{Na}$ minha vida até que eu tô viva, nunca mais vou esquecer. Era um vidro de shampoo seda, cor de rosa, e eu comprei pra mim. E daí ainda sobrou dinheiro e eu levei tudo pra casa, pra mãe. Daí quando eu cheguei em casa, e aquele véio viu aquilo (silêncio). Eu achei que ele ia me matar, porque eu comprei aquele shampoo. Maquiagem na minha vida eu nunca tive, eu não tive batom, não tinha base, não tinha esmalte, não podia.

Considerando a faixa etária de mulheres com menos de 30 anos, as trajetórias de vida narradas trazem elementos distintos acerca de suas relações com o trabalho e com o acesso a educação escolar, relatando inclusive experiências de formação no Ensino Superior, como é o caso de Tina, 26 anos, recentemente formada em Administração, trabalhando em uma farmácia e, no momento da entrevista, em licença maternidade.

- Pois é, como eu trabalhei um ano no escritório de contabilidade, foi uma experiência assim que eu gostei bastante, sabe? Então eu queria ir mais pra esse lado sabe, tipo um escritório, alguma coisa assim sabe, porque eu gosto muito dessa parte também né. Então na verdade eu tô em busca né, pra ver se vai surgir alguma coisa. Mas aqui em Santa Maria do Herval é meio complicado, não tem muito opção assim de emprego, então eu vou esperar, vamos ver quando surgir alguma coisa... Eu acho que em qualquer emprego que eu vou tá eu quero tá feliz. Independente do emprego, acho que a gente tem que se adaptar a qualquer emprego assim.

No entanto, o maior acesso à escolaridade, inclusive ao Ensino Superior, nos parece que ainda não foi acompanhado pela possibilidade de se inserir em postos de trabalho no município condizentes com a formação escolhida, possibilitando a permanência na comunidade.

\section{Considerações Finais}

Ao estudarmos as trajetórias de vida, cabe destacar que não as compreendemos como relatos objetivos, lógicos, cronológicos e lineares que as mulheres apresentaram de suas experiências. Entendemos que os relatos de tais trajetórias resultam em narrativas, construídas por essas mulheres e reconstruídas analiticamente na pesquisa. Sendo assim, o trabalho analítico dessas narrativas foi o de investigar de que maneira tais trajetórias singulares de 
formação e trabalho incorporam as experiências e os processos socioculturais de uma comunidade, uma região e um país (Kofes, 2007; Mintz, 1984).

Retomando o conceito de qualidade de vida apresentado anteriormente, consideramos que os relatos demonstram que o trabalho das mulheres nas fábricas de calçado promoveu uma maior estabilidade financeira para as famílias, resultando na possibilidade da manutenção de seus modos de vida na comunidade. Entretanto, o acesso das mulheres mais jovens a maior escolarização, e até mesmo ao Ensino Superior, aumentou as suas capacidades, mas ainda não teve impacto em termos das funcionalidades que estas podem desempenhar na comunidade. Desta forma, o campo e as atividades a ele relacionadas são narrados como um local de atraso, da exaustão física, emocional e do controle patriarcal; a fábrica de calçados, por sua vez, já não se configura como o espaço da realização financeira, mas continua sendo a opção de trabalho acessível na comunidade - se continua nele até que se alcance algo melhor, o que por vezes pode significar uma mudança de cidade.

A partir destas análises, compreendemos os dois movimentos de pesquisa apresentados trazem preciosas contribuições para que seja pensada a organização da comunidade, principalmente em termos de alternativas de trabalho e estratégias educativas em Educação do Campo que sejam capazes de promover a sucessão geracional da agricultura familiar no município e de incorporar a temática de gênero, gerando assim um real incremento em termos de qualidade de vida desta população.

\section{Referências}

Braun, A. D., Johann, S. M. H., \& Schimit, S. J. (2009). Do Velho Mundo para o BUCHERBERG ou BUCHERBERG um Novo Mundo!!! Nova Petrópolis, RS: Editora Amstad.

CNE/CEB. (2002). Resolução CNE/CEB 1, de 3 de abril de 2002. Recuperado de: http://portal.mec.gov.br/index.php?option= com_docman\&view=download\&alias $=138$ 00-rceb001-02pdf\&category_slug=agosto-2013pdf\&Itemid $=30192$

- (2007). Parecer CNE/CEB $n^{o}$ 23/2007, aprovado em 12 de setembro de 2007. Recuperado de: http://portal.mec.gov.br/index.php?option= com_docman\&view=download\&alias $=143$ 44-pceb023-07\&category_slug=outubro2013-pdf\&Itemid=30192

Gaviria, M. R., \& Menasche, R. (2006) A juventude rural no desenvolvimento territorial: análise da posição e do papel dos jovens no processo de transformação do campo. Estudo \& Debate, 13(1), 69-82.

Gaviria, M. R., \& Pezzi, S. M. (2007). O poder simbólico da renda na mobilização social de jovens de comunidades rurais. In Menasche, R. (Org.). A agricultura familiar à mesa: saberes e práticas da 
alimentação no Vale do Taquari (pp. 4357). Porto Alegre, RS: Editora da UFRGS.

Helman, C. G. (2009). Cultura, Saúde e Doença. Porto Alegre/RS: Artmed.

IBGE. (2014). Cidades@. Recuperado de: http://cod.ibge.gov.br/cxc

Kofes, S. (2007). Experiências sociais, interpretações individuais: Histórias de vida, suas possibilidades e limites. Cadernos Pagu, 3, 117-141. Recuperado de:

https://periodicos.sbu.unicamp.br/ojs/index .php/cadpagu/article/view/1725t

Louro, G. L., Neckel, J. F., \& Goellner, S. V. (Orgs.) (2003). Corpo, gênero $e$ sexualidade: um debate contemporâneo na educação. Petrópolis, RJ: Vozes.

Machado, C. J. B., \& Menasche, R. (2012). Trabalho de homem, trabalho de mulher: olhares sobre a organização do lote a partir da produção. In Anais do Seminário Internacional Fazendo Gênero 10 (pp. 112). Florianópolis, SC.

Maia, C. J. (2004). Trabalho, família e gênero: estratégias de reprodução social camponesa no Médio Jequitinhonha. Mulher e trabalho, 4, 89-103.

MEC/CNE (2001). Diretrizes Operacionais para a Educação Básica nas Escolas do Campo. Recuperado de: http://pronacampo.mec.gov.br/images/pdf/ mn_parecer_36_de_04_de_dezembro_de 2001.pdf

Mintz, S. W. (1984). Encontrando Taso, me descobrindo. Revista de Ciências Sociais, 27(1), 45-58.

Sen, A. K. (2001). Desigualdade reexaminada. Rio de Janeiro, RJ: Record.

Schneider, S., \& Freitas, T. D. (2013). Qualidade de vida, diversificação e desenvolvimento: referências práticas para análise do bem-estar no meio rural. Olhares Sociais, 2(1), 121-142.

Schneider, S. (2004). Agricultura familiar $e$ industrialização: pluriatividade $e$ descentralização industrial no Rio Grande do Sul. Porto Alegre, RS: Editora da UFRGS.

Sposito, M. E. B. (2009). Introdução. In Saquet, M. A., \& Sposito, E. S. (Orgs.) Território e Territorialidades: teorias, processos e conflitos (pp. 11-16). São Paulo, SP: Expressão Popular.

Stropasolas, V. L. (2011). Os desafios da sucessão geracional na agricultura familiar. Agriculturas, 8(1), 26-29.

Wedig, J. C., \& Menasche, R.(2009). Entre o campo e a cidade: o lugar do consumo na mobilidade material e simbólica de jovens rurais. In Pinto, M. L., Pacheco, J. K. (Orgs.) Juventude, Consumo \& Educação 2 (pp. 95-112). Porto Alegre,RS: ESPM.

Woortmann, E. F. (2000). Identidades e memória entre teuto-brasileiros. Horizontes Antropológicos, 6(14), 205238.

\footnotetext{
i O hunsrik é a língua germânica mais falada no Rio Grande do Sul. Ágrafa até 2004, ela é cotidianamente usada por quase dois milhões de pessoas no Brasil, com forte presença em comunidades de colonização germânica. Utilizamos o itálico para destacar os termos utilizados na língua hunsrik, assim como para outros termos em línguas estrangeiras.
}

ii Região na qual chegaram os primeiros grupos de imigrantes alemães no estado do Rio Grande do Sul, a partir de 1824

iii Identidade de gênero é a experiência subjetiva de uma pessoa a respeito de si mesma e das suas relações com outros gêneros. Não depende do sexo biológico da pessoa, mas de como ela se percebe. Essa identidade pode ser binária (homem ou 
mulher), mas também pode ir além dessas representações e rechaçar ambas as possibilidades de reconhecimento, sendo assim pessoas nãobinárias (todos os outros gêneros). Neste sentido, o gênero é uma ferramenta para a desnaturalização, apontando para os muitos significados de masculinidades e feminilidades que se articulam a muitas 'marcas' sociais, como classe, etnia, entre outras (Louro et al, 2003).

iv Consideramos territorialidade no sentido afirmado por Sposito (2009), como sendo aquilo que designa a qualidade que o território ganha de acordo com a sua utilização ou apreensão pelo ser humano.

$\checkmark$ Como, por exemplo, cursos relacionados à fabricação de pães, bolos, conservas e compotas.

vi Vale relembrar que segundo os dados mais atualizados do IBGE, datados de 2014, a população do município é de 6.295 habitantes.

\section{Informações do artigo / Article Information \\ Recebido em : 30/05/2018 \\ Aprovado em: 17/09/2018 \\ Publicado em: 23/12/2018 \\ Received on May 30th, 2018 \\ Accepted on September 17th, 2018 \\ Published on December 23th, 2018}

Contribuições no artigo: As autoras foram responsáveis pela elaboração, análise e interpretação dos dados; escrita e revisão do conteúdo do artigo, e aprovação da versão final publicada.

Author Contributions: The authors were responsible for the designing, delineating, analyzing and interpreting the data, production of the manuscript, critical revision of the content and approval of the final version published.

Conflitos de interesse: As autoras declararam não haver nenhum conflito de interesse referente a este artigo.

Conflict of Interest: None reported.

\section{Orcid}

Tatiana Souza de Camargo

iD http://orcid.org/0000-0001-9179-7470

Muriel Closs Boeff

iD http://orcid.org/0000-0002-7248-3609

\section{Como citar este artigo / How to cite this article}

APA

Camargo, T. S., \& Boeff, M. C. (2018). Mulheres, trabalhos e histórias: uma análise das trajetórias de vida em uma Comunidade Teuto-Brasileira do RS. Rev. Bras. Educ. Camp., 3(4), 1202-1220. DOI: http://dx.doi.org/10.20873/uft.2525-4863.2018v3n4p1202

ABNT

CAMARGO, T. S.; BOEFF, M. C. Mulheres, trabalhos e histórias: uma análise das trajetórias de vida em uma Comunidade Teuto-Brasileira do RS. Rev. Bras. Educ. Camp., Tocantinópolis, v. 3, n. 4, set./dez., p. 1202-1220, 2018. DOI: http://dx.doi.org/10.20873/uft.2525$\underline{4863.2018 v 3 n 4 p 1202}$ 